OPEN ACCESS

Edited by:

Tiziana Rossetto,

University College London,

United Kingdom

Reviewed by:

Xinzheng Lu,

Tsinghua University, China

Utku Kanoglu,

Middle East Technical University,

Turkey

*Correspondence:

Pedro Lomonaco

pedro.Iomonaco@oregonstate.edu

Specialty section:

This article was submitted to

Earthquake Engineering,

a section of the journal

Frontiers in Built Environment

Received: 03 July 2020 Accepted: 08 October 2020 Published: 30 October 2020

Citation:

Lomonaco P, Cox D, Higgins C, Maddux T, Bosma B, Miller $R$ and

Batti J (2020) Building Resilient

Coastal Communities: The NHERI Experimental Facility for Surge, Wave,

and Tsunami Hazards.

Front. Built Environ. 6:579729.

doi: 10.3389/fbuil.2020.579729

\section{Building Resilient Coastal Communities: The NHERI Experimental Facility for Surge, Wave, and Tsunami Hazards}

\author{
Pedro Lomonaco ${ }^{1,2 *}$, Daniel Cox ${ }^{1,2}$, Christopher Higgins ${ }^{1,2}$, Timothy Maddux ${ }^{1,2}$, \\ Bret Bosma ${ }^{1,2}$, Rebekah Miller ${ }^{1,2}$ and James Batti ${ }^{1,2}$ \\ ${ }^{1}$ O.H. Hinsdale Wave Research Laboratory, Oregon State University, Corvallis, OR, United States, ${ }^{2}$ School of Civil \\ and Construction Engineering, Oregon State University, Corvallis, OR, United States
}

Through the Natural Hazards Engineering Research Infrastructure program (NHERI) established by the National Science Foundation in the United States, a suite of experimental facilities has been made available to the research community to advance the resilience of civil infrastructure and communities to coastal storm and earthquake hazards. A NHERI Experimental Facility, hosted at the O.H. Hinsdale Wave Research Laboratory at Oregon State University (HWRL EF), was created through this program that serves as a state-of-the-art engineering research, education, and outreach center related to tsunamis caused by earthquakes and coastal waves and surge caused by windstorms. HWRL EF includes two specialized large-scale resources for physical model testing of coastal systems: a large wave flume (LWF) and a directional wave basin (DWB). These facilities are available to the research community to address grand challenges relating to tsunami and coastal windstorm surge and wave hazards impacting the built and natural environments. This paper describes the capabilities of the HWRL EF and presents 10 example projects conducted under NHERI since 2016. The research projects highlight the broad scientific interest and potential application of physical model testing in multi-hazard mitigation and resilience in coastal communities.

Keywords: coastal structures, waves, surge, tsunami, experimentation (laboratory tests), resilience, natural hazards and disasters

\section{INTRODUCTION}

The Natural Hazards Engineering Research Infrastructure (NHERI) program is supported by the US National Science Foundation (NSF) since 2016 to enable a distributed, multi-user, national facility that will provide the natural hazards engineering community with access to research infrastructure coupled with education and community outreach activities. NHERI enables research and educational advances that can contribute knowledge and innovation for the nation's civil infrastructure and communities to prevent natural hazard events from becoming societal disasters. NHERI consists of 12 components: the Network Coordination Office (NCO), cyberinfrastructure for collaboration and data archival (DesignSafe-CI), seven Experimental Facilities (EFs) for seismic and windstorm disasters, a disaster reconnaissance equipment facility (RAPID), a CONVERGE facility to coordinate reconnaissance research, and a computer modeling facility (SimCenter). 
The purpose of this paper is to describe the NHERI Experimental Facility hosted at the O.H. Hinsdale Wave Research Laboratory at Oregon State University (HWRL EF for brevity). The HWRL EF supports the broader vision of NHERI to increase the resilience of civil infrastructure and communities to coastal windstorms and tsunamis (NHERI Science Plan, 2020) along the lines of these three grand challenges:

1. Identify and quantify the characteristics of tsunamis, storm surge, and waves hazards due to earthquakes and windstorm that are damaging to civil infrastructure and disruptive to communities.

2. Assess the physical vulnerability of civil infrastructure and the social vulnerability of populations in communities exposed to earthquakes, windstorms, and associated hazards.

3. Create the technologies and engineering tools to design, construct, retrofit, and operate a multi-hazard resilient and sustainable infrastructure for the nation.

The science drivers for HWRL EF can be found in the NHERI Science Plan (2020), and more detailed information is contained in a number of guidance documents for research related to hurricanes and tsunamis (NSTC, 2006; NSB, 2007; NIST, 2014; NRC, 2011, 2012, 2014).

The research gaps for surge, wave and tsunamis in the NHERI Science Plan was initially drafted by the first and second authors of this paper. Therefore, much of the text in this section is included verbatim from the NHERI Science Plan:

Surge, Wave, and Tsunami Inundation Hazards: A grand challenge for overland flow is to model the hazard intensity over scales ranging from entire regions (several hundred kilometers) to subassemblies of structures (several meters). The current state of the practice assumes "bare earth" models, meaning that the effect of the built environment is not modeled in detail even though it is known that the built environment has significant influence on the local flow field. Other key research questions include how to account for the time-varying conditions-for example, the changing bathymetry and topography due to coastal erosion and roughness due to damage/failure of buildings and other infrastructure. Additional challenges related to overland hazard include the quantification of flood-borne debris hazards that are related to debris impact, debris damming, and debris removal challenges. The inundation and subsequent return flow also generate significant currents and other navigational hazards. It is generally accepted that velocity is more difficult to quantify than the water level, so the generation of current hazards remains an open area of research. The generation of tsunamis from landslides is also an open area of research (NHERI Science Plan, 2020).

Surge, Wave, and Tsunami Loads: Estimating surge, wave and tsunami loads on coastal infrastructure, including buildings, water, power, transportation, and communication lifelines, remains an engineering grand challenge. Although significant progress has been made for offshore and coastal structures which regularly experience extreme wave loads, similar progress has not been made for near-coast structures for which these conditions are rare but have high consequence. Our ability to predict the pressure distributions for both horizontal and uplift loads accurately remains a challenge. Moreover, because the wave climate is random in nature, the wave loading will follow a statistical distribution different from deep water conditions because of depth-limited breaking in shallow water. The probabilistic nature of extreme wave loads for a given sea state remains an open research question. The effects of cyclic loading from long-duration storms, multiple storms, and/or multiple tsunami waves, particularly cyclic loading from conditions less than the design conditions and its impacts on coastal infrastructure, is an important research area (NHERI Science Plan, 2020).

Related to the issue of wave loads, additional challenges include surge, wave and tsunami damage functions. Some progress has been made since the 2004 Indian Ocean tsunami and the 2011 Japan tsunami to develop empirical fragility curves for buildings and bridges. Additional work has been done to develop flood damage functions that may be suitable for coastal environments. However, the development of probabilistic approaches for community scale risk assessment remains a grand challenge. Load combinations for simultaneous flood hazards such as the static buoyancy due to flooding, the hydrodynamic drag due to currents, and the impulsive forces due to waves remains a research question. Performance-based design for coastal structures also remains a research question. Building performance over the lifecycle of the building/infrastructure accounting for conditions specific to the coastal environment like corrosion and their impact on design performance are important research questions (NHERI Science Plan, 2020).

Coastal Erosion and Scour: The US and many countries rely on coastal beaches and dunes to mitigate the effects of extreme storm surges. A grand challenge is to account for coastal erosion during extreme events to quantify overtopping of dunes, revetments, seawalls and other protective measures to mitigate storm surge. Moreover, coastal infrastructure including pile foundations, on-grade construction, seawalls, surface transportation, and buried pipelines depend on an understanding of the local scour to design resilient and adaptive infrastructure (NHERI Science Plan, 2020).

Natural and Nature-Based Features for Coastal Hazard Mitigation: Similar to our reliance on beach nourishment and dune construction, coastal communities in the world rely on natural and nature-based features (NNBF, also termed "Engineering with Nature") including coastal reefs, wetland features, and coastal forests including mangroves for coastal hazard mitigation. NNBF provides a wide range of benefits including economic and ecological functions and maybe suitable for adaptation to climate change. Although the ecological goods and services are reasonably well known, the capacity of such systems to provide adequate protection is still an open research question. These engineered systems are also expected to change over seasonal and decadal time scales, further complicating our understanding of the performance of these systems and use in engineering design. The integration of such systems into multiple lines of defense also remains on open research question (NHERI Science Plan, 2020). 
Numerical Model Development and Benchmarking: Significant progress has been made on numerical modeling of hydraulic flows at a range of scales. Direct Numerical Simulation (DNS) is only feasible at scales much smaller than what is necessary for coastal engineering, therefore suitable methods for turbulence closure remain a challenge. Additional challenges include multi-phase flow, such as air-water-sediment. For example, accounting for air entrainment is necessary to capture impulsive breaking waves and the uplift for complex shapes which frequently trap air. The coupling of fluid structure models is also a research question. Local wave impact and structural component elasticity occur at a significantly smaller time scale (micro- to milli-seconds) than the surge, wave and tsunami load durations (seconds to kilo-seconds), necessitating multiphysics models and multi-time scale computation. Enforcing interface compatibility and matching time step are paramount for accurate long-term response prediction. Additional topics for numerical modeling and benchmarking include wave and tsunami runup, wave breaking and bottom boundary layer turbulence, sediment suspension and transport, and multiphase (air-water-sediment) dynamics (NHERI Science Plan, 2020).

\section{FACILITY OVERVIEW}

The HWRL EF is located in the O.H. Hinsdale Wave Research Laboratory (HWRL) on the Oregon State University main campus in Corvallis, Oregon (Figure 1) and is part of the School of Civil and Construction Engineering (CCE) in the College of Engineering. The HWRL is comprised of two clear-span buildings comprising a total of $5,480 \mathrm{~m}^{2}\left(59,000 \mathrm{ft}^{2}\right)$ of laboratory space. Within these buildings, there is approximately $464 \mathrm{~m}^{2}$ $\left(5,000 \mathrm{ft}^{2}\right)$ of office space, including a large conference room, office space for visitors, a large work area for students, office space for staff, control room, an instrumentation room, a model shop area with tools, materials and supplies, and an area for health and safety equipment.

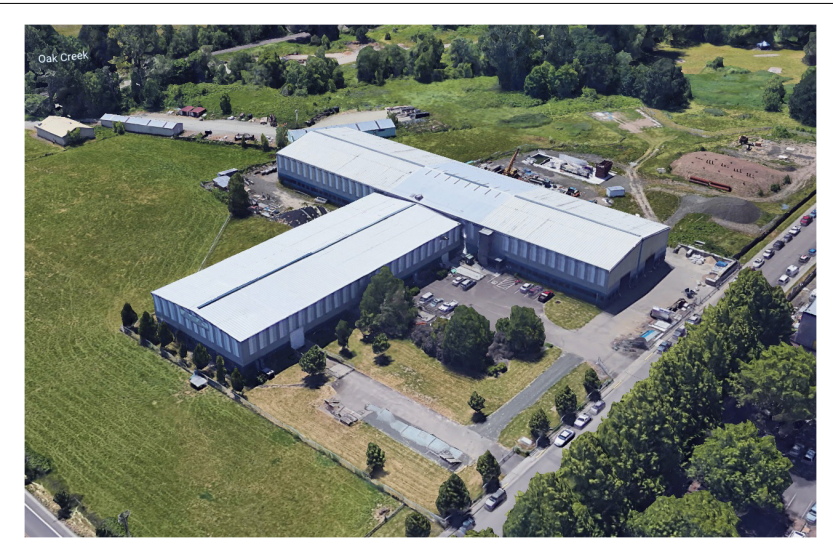

FIGURE 1 | Aerial view of O.H. Hinsdale Wave Research Laboratory. Image: Google Maps.
The HWRL has two major pieces of experimental equipment: the Large Wave Flume (LWF) and the Directional Wave Basin (DWB), described in detail in the following paragraphs.

It is worth mentioning that the LWF is the largest wave flume in the United States. The size of the flume enables scaling effects to be minimized in several research projects relevant to the NHERI research. The DWB has the largest wave generator of its kind in the US, allowing it to generate long waves (i.e., tsunami-like waves and other transient waves) unlike any other facility in the US. There is no other coastal facility in the US that can be used for wave-structure interaction of building systems at this scale. The LWF and DWB were specifically designed for coastal engineering research. Finally, the LWF and DWB are hosted by an academic institution and allow access by users at other universities.

\section{Large Wave Flume}

The Large Wave Flume (Figure 2) is the largest of its kind in the US. Because of its size and ability to operate in high Reynolds regimes, the flume is ideally suited for a wide range of testing, including but not limited to cross-shore sediment suspension and transport; wave forces on offshore and coastal structures; nearshore hydrodynamics; wave breaking, swash dynamics, and undertow; tsunami inundation and overland flow; tsunami structure impact, debris and scour; pollutant mixing and transport; scour, pipeline stability and outfalls; liquefaction, cohesive sediments; wave runup, reflection, and overtopping; ocean wave energy systems; as well as natural and nature-based coastal engineering. The LWF specifications are $104 \mathrm{~m}(342 \mathrm{ft})$ in length, $3.7 \mathrm{~m}(12 \mathrm{ft})$ in width, and $4.6 \mathrm{~m}(15 \mathrm{ft})$ in height. The maximum water depth is 2 $\mathrm{m}(6.56 \mathrm{ft})$ for tsunami, and $2.74 \mathrm{~m}(9 \mathrm{ft})$ for windstorm waves. The wavemaker is a dry-back piston-type with hydraulic actuator assembly with active wave absorption and is capable of generating regular, irregular, solitary or tsunami-like waves (Figure 3, left). The wavemaker can generate user-defined waves in a period range from 0.8 to $12+$ seconds. The maximum wave is $1.7 \mathrm{~m}(5.6 \mathrm{ft})$ at $5 \mathrm{~s}$ in a maximum of $2.74 \mathrm{~m}$ water depth. The maximum tsunami-like wave is $1.4 \mathrm{~m}(3.9 \mathrm{ft})$ in a maximum water depth of $2.0 \mathrm{~m}$. The maximum stroke is $4 \mathrm{~m}(13.1 \mathrm{ft})$ at $4 \mathrm{~m} / \mathrm{s}(13.1 \mathrm{ft} / \mathrm{s})$. The LWF is equipped with a piecewise-continuous, movable, impermeable slope and can be adjusted to 1:12, 1:24, 1:36 and flat. The LWF is equipped with an instrumentation carriage with full cross-shore traverse and carriage-mounted vertical instrument deployment frame. The LWF also has a lightweight carriage for video and lighting applications.

\section{Directional Wave Basin}

The Directional Wave Basin (Figure 4) was designed to understand the fundamental nature of tsunami inundation, tsunami-structure impact, harbor resonance and 3D wave propagation. The DWB is particularly suited for the general testing of coastal infrastructures, nearshore processes research, wave hydrodynamics, near-coast structures such as buildings, floating structures, renewable energy devices, and numerical model validation. 
The DWB specifications are $48.8 \mathrm{~m}$ (160 ft) in length, 26.5 $\mathrm{m}(87 \mathrm{ft})$ in width, and $2.1 \mathrm{~m}(7 \mathrm{ft})$ in height. The maximum water depth is $1.5 \mathrm{~m}(4.46 \mathrm{ft})$. The wavemaker is a unique snake-type system made of 29 boards and 30 actuators with up to $2.1 \mathrm{~m}$ long stroke. It has been designed to generate short- and long-period multidirectional high-quality waves. The drive system is a wet-back piston-type, electric motor. The wavemaker is capable of delivering regular, irregular, tsunami, multidirectional, and user defined waves (Figure 3, right). The period range is $0.5-10+$ seconds. The maximum regular wave is $0.85 \mathrm{~m}(2.5 \mathrm{ft})$ in $1.37 \mathrm{~m}(4.5 \mathrm{ft})$ water. The maximum solitary (tsunami-like) wave is $0.7 \mathrm{~m}$ in $1.0 \mathrm{~m}$ water depth. The maximum stroke of the wavemaker is $2.1 \mathrm{~m}(6.9 \mathrm{ft})$, and the maximum velocity is $2.0 \mathrm{~m} / \mathrm{s}(6.6 \mathrm{ft} / \mathrm{s})$. The DWB is equipped with a 1:10 removable steel beach. The DWB is equipped with the following supporting infrastructure: a 7.5 ton capacity bridge crane spanning the $2,137 \mathrm{~m}^{2}\left(23,000 \mathrm{ft}^{2}\right)$ space, and instrumentation carriage spanning the $26.5 \mathrm{~m}$ width of the basin, Unistrut $(\subset$ installed in floor and sides to secure models, and two access ramps, $2.74 \mathrm{~m}(9 \mathrm{ft})$ and $4.2 \mathrm{~m}(14 \mathrm{ft})$ wide. Steady flow currents can be installed on a project-byproject basis.

\section{Instrumentation and Equipment}

The HWRL has a large inventory of state-of-the art and conventional instrumentation to measure hydrodynamics (free surface, velocity, wave pressure), sediment response (turbidity, sediment suspension, scour, pore-pressure), and structural response (force, pressure, stress, displacement, acceleration). The free surface can be measured with surface-piercing resistancetype paired-wire wave gages using seven 8 channel signal conditioners (ImTech), 6 self-calibrating wave gage mounts for the LWF, 7 self-calibrating wave gage mounts for the DWB, 13 fixed wave gage mounts for the LWF, 19 fixed wave gage mounts for the DWB, 18 cantilever gage mounts, and 26 runup gage mounts. The HWRL also has 8 acoustic wave gages.
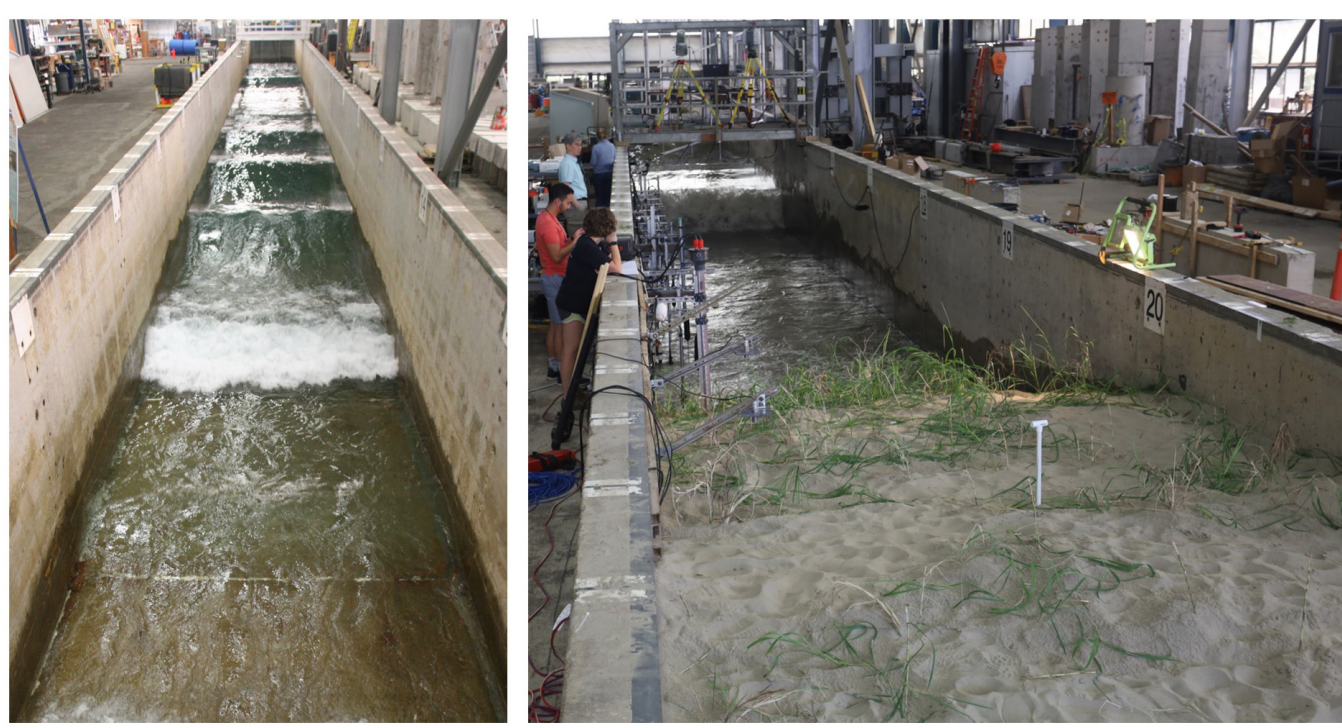

FIGURE 2 | Large Wave Flume overview (left) and use of LWF for dune erosion study (right).
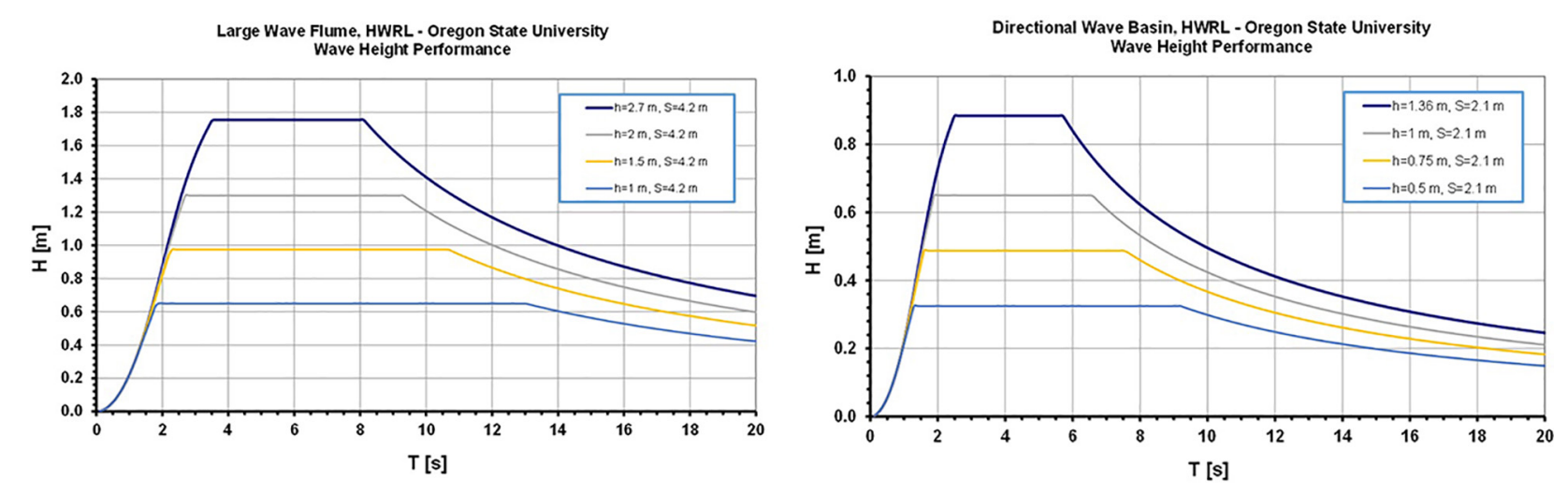

FIGURE 3 | Wavemaker performance for LWF (left) and DWB (right). 
The velocity can be measured with 16 3-D acoustic-Doppler velocimeter (Nortek Vectrino) and 4 2-D acoustic-Doppler velocimeter probe heads. Fluid pressure can be measured with 5 pore pressure transducers (Druck PDCR81), 24 pressure transducers (12 Druck PDCR830 and 12 PDCR1830). Four $10 \mathrm{ch}$ and one 4ch signal conditioners (Vishay 2100), four $222 \mathrm{kN}$ (50Kip) and four $89 \mathrm{kN}$ (20Kip) pancake load cells (DeltaMetrics), two $44.5 \mathrm{kN}$ (10Kip), six $9 \mathrm{kN}$ (2Kip) rod end load cells (DeltaMetrics), and one $18 \mathrm{kN} / 2 \mathrm{kNm}$ submersible multi-axial load cell. Turbidity can be measured with 16 optical backscatter sensors (D\&A Instr., OBS-3). The bathymetry can be measured with two 32-component ultrasonic ranging system (SeaTek), four laser range finder 0.2-200 m (Dimetix DLSA30), and a Leica BLK 360 Laser Scanner. Displacement can be measured with PhaseSpace Motion Capture system (8 cameras), 6 string potentiometers, LDVT and encoders. Video recording is possible with $6 \mathrm{PTZ} \mathrm{HD} 1080 \mathrm{p}$ cameras, 2 submersible HD $720 \mathrm{p}$ underwater cameras and lights, 6 PIX SSD-based HD video recording systems, and waterproof (GoPro) and handheld (Sony) HD cameras.

The data acquisition system (DAQ) consists of 3 modular PXI architecture DAQ systems from National Instruments, each with built-in signal conditioning and anti-aliasing, 64 channel, 16-bit analog acquisition, digital pulse generation, external device synchronization and up to16 channel RS232 for serial communication. The DAQs can be synched to provide 192 analog channels and 48 digital channels with two additional modular PXI architecture DAQ systems. The HWRL is equipped with six PTZ web cameras (Axis) to view experiments remotely.

Wireless and wired networking and switches at the HWRL EF are supported by the College of Engineering IT group and by OSU Network Services. The fiber to the building was upgraded to a total of 10 Gbps with switches providing 1 Gbps links to every host system on the public network. Systems on the private firewalled DAQ network share a single 1 Gbps link to the outside and have $100 \mathrm{Mbps}$ connectivity per DAQ host system. The wireless system at the HWRL $\mathrm{EF}$ is currently running dual-band $802.11 \mathrm{n}$ and hosts both open (public) access for visitors or guests and secure (WPA2) access for OSU only.

The HWRL EF has a full site safety plan and set of protocols that are available online for review by all potential visitors and users. The plan and protocols include mandatory documented training for any user prior to starting work at the EF. It also includes protocols for regular inspections and weekly safety meetings and reviews. The HWRL EF provides all staff and visitors personal protective equipment (PPE) including eye protection, ear protection, protective gloves, hard hats, dust masks and other PPE.

The HWRL EF can be accessed by roll up doors for entry by trucks and other equipment to offload specimens. Each door is $4.3 \mathrm{~m}$ (14 ft) wide by approximately $4.9 \mathrm{~m}$ (16 ft) tall. The HWRL EF has four pieces of heavy machinery operated by HWRL EF staff to support specimen handling, transport, and staging. These include two forklifts (5,000 and 10,000 lb), a bucket loader, and a large shooting-boom forklift $(10,000 \mathrm{lb})$. Additional equipment for specimen staging or demolition is contracted out on a perproject basis. The HWRL EF is served by of a 7.5-ton bridge crane over the DWB and a 6-ton gantry crane over the LWF.

Upon request, the HWRL EF can work with users to procure other services and tools necessary for experimentation which are not listed here. Examples include local subcontractors for specimen construction, installation or removal; the addition of pumps for steady currents; or rental of industrial equipment not available on-site.

\section{EXAMPLE RESEARCH PROJECTS FOR NHERI 2016-2019}

This section highlights the accomplishments of 10 projects conducted under the current NHERI HWRL EF award. Table 1
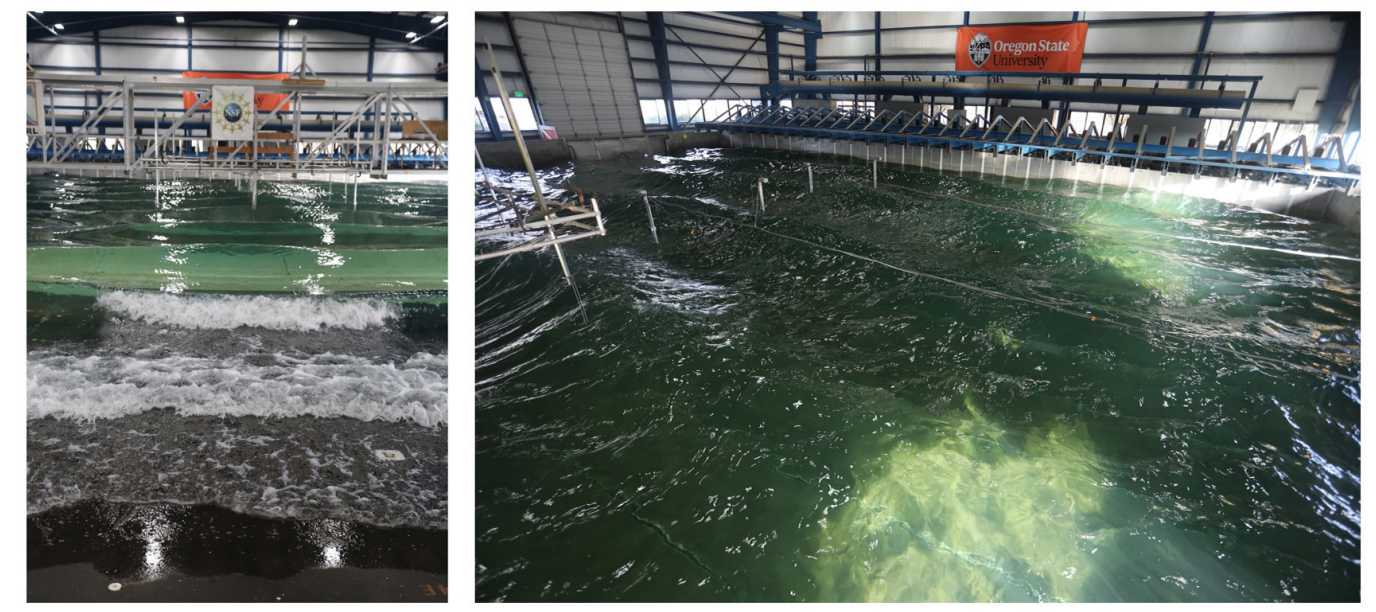

FIGURE 4 | Overview of Directional Wave Basin (left) and wavemaker detail (right). 
TABLE 1 | Projects conducted in the NHERI HWRL EF.



NSF ID is the National Science Foundation project identification, $N_{d a}$ is the number of days of testing, and $N_{t r}$ is the number of trials.

lists the projects tested at the HWRL EF under the NHERI program, including the project identification (ID), the Principal Investigators (PIs), institution(s), project title, facility used (LWF, $\mathrm{DWB})$, year, number of days of testing (Nda), and the number of trials (Ntr). There were 14 projects to use the facility, of which 6 were Collaborative Proposals. Of the 25 researchers listed in the table, an overwhelming majority $(n=21,84 \%)$ were from outside the host institution and a majority $(n=15$, $60 \%)$ were new users. A majority of the institutions $(n=8$, $57 \%$ ) were new to the facility. In summary, this table indicates that the HWRL EF was highly effective as a shared-use facility. Highlights include summaries of the research awards posted on NSF Fastlane and edited for brevity and relevance to NHERI EF. Publications from each project is provided in the references section.

\section{Collaborative Research: Fundamental Mechanics and Conditional Probabilities for Prediction of Hurricane Surge and Wave Loads on Elevated Coastal Structures}

Damage to coastal structures as a result of combined surge and wave loading has been significant in recent events such as Hurricane Ivan (2004), Katrina (2005), Ike (2008) and Sandy (2012), and most recently Matthew (2016), Harvey, Irma, Maria (2017), Florence, Michael (2018), and Humberto (2019). This project focused on the impact of hurricane surge and wave loads on elevated coastal structures to understand and quantify surge and wave loads on buildings and structures that can be used to mitigate damage to the coastal structures. This collaborative 
project between research teams at Oregon State University and Colorado State University have combined expertise in coastal engineering and structural engineering to develop a fundamental understanding and modeling of hurricane surge and wave loads on elevated structures. The goal is to mitigate damages to shoreline infrastructures from extreme coastal storms. The analytical formulation was built on Goda's method for calculating surge forces on elevated coastal structures and have been extended to incorporate wave forces. A probabilistic approach was taken to combine surge and wave loads. Hydrodynamic hurricane wave and structure interaction were used to formulate loading on these types of structures. The formulations were validated with experiments using the LWF.

The NHERI HWRL EF developed an innovative test apparatus for independent measurements of horizontal and vertical forces of waves and tsunamis impacting an elevated coastal structure while still allowing for the entire assembly to be raised and lowered to study the role of freeboard (airgap) on the overall forces experienced by the structure (Figure 5). The researchers found that the maximum uplift pressures were observed when the mean water level was at the lowest horizontal member (Park et al., 2017, 2019). The data collected for this project has been used to develop new design equations proposed for the next cycle of the ASCE 7 standard in 2022 (Tomiczek et al., 2018, 2019a,b). The detailed observations of impact pressure under breaking, broken, and near breaking waves were compared with two high-resolution numerical models, OpenFOAM and Fluent, quantify uncertainties with respect to model schemes and grid resolution (Park et al., 2018a,b). This project contributed to the career development of 1 postdoctoral scholar, 2 Ph.D. students, 2 MSc students from the US Navy, and 2 Research Experience for Undergraduate (REU) students from the University of Puerto Rico in Mayaguez (UPR-Mayaguez).

\section{Collaborative Research: Non-linear Long Wave Amplification in the Shadow Zone of Offshore Islands}

Field survey reports from recent tsunamis suggest that local residents in mainland areas shadowed by nearby islands may be under the impression that these islands protect them from tsunamis. Recent numerical results have generated substantial attention because they suggest that, in most cases, islands amplify tsunamis in the shadow zones behind them. In this application, the active learning methodology requires about 100,000 times fewer computations than conventional mathematical approaches, and it is unclear if the amplification effect is real. Through comprehensive laboratory experiments, the physical manifestation of this effect was studied. If indeed the physical experiments confirm the numerical idealizations, this research will help save lives by better targeting educational campaigns to at risk populations. For example, it will be determined if coastlines shadowed by offshore islands along the Pacific Coast of the US are more vulnerable than earlier believed. The early numerical results from active learning are only applicable for non-breaking waves. Through the laboratory experiments, it was determined if this vexing phenomenon persists when waves break. The results will help validate active learning as a mathematical procedure for uncertainty reduction which greatly reduces computational costs. Laboratory data helped to benchmark numerical computations.

This project provided one of the first laboratory measurements of hydrodynamic conditions of the near-field and far-field effects of offshore islands on tsunami run-up. The HWRL EF assisted researchers from the University of Southern California and Texas A\&M University with the construction of 4 large-scale, geometrically accurate conical islands available for this project and further testing to the scientific community (Figure 6). The HWRL EF assisted with LiDAR (Laser Scanner) to provide highly resolved bathymetric conditions for interpretation of hydrodynamic conditions and for numerical modeling. Researchers used optical measurement techniques (i.e., Particle Tracking and Particle Image Velocimetry-PTV and PIV) to capture the flow around the two islands (Lynett et al., 2019), and used novel techniques to measure the run-up around the island (Kaihatu et al., 2018; Han et al., 2020). These experiments generated a detailed data set for the calibration of an open source code based on the extended Boussinesq equations for interactive and real-time wave simulation (Lynett, 2016). This project identified an increased risk of run-up on the leeside of the
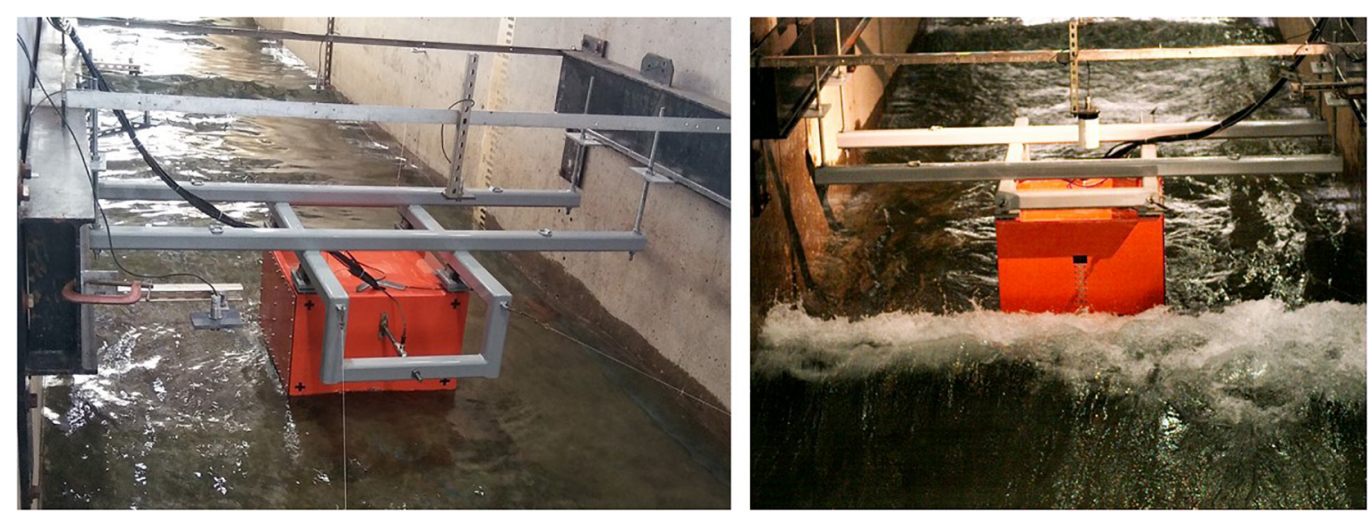

FIGURE 5 | Lee-side of the specimen (left) and wave impacting elevated structure (right). 
islands under certain conditions (Keen and Lynett, 2019). Two comprehensive test campaigns were conducted with single and multi-island layout. Three Ph.D. students and 4 REU students were involved. The project included informal collaborations with researchers from Chile.

\section{Probabilistic Assessment of Tsunami Forces on Coastal Structures}

Interest in tsunami load predictions for structural design has grown, but it is difficult to develop models that accurately predict the tsunami load response of an individual structure, much less the tsunami risk for multiple structures within a specific region. This project was designed to improve the safety and sustainability of coastal structures and, consequently, improve tsunami hazard assessments, post-event response, and recovery efforts. The primary goals of this research project were to establish an open-source modeling framework where 3D computational fluid dynamics solvers can be used efficiently to inform the development of load-prediction capabilities for existing, widely used inundation models and to develop a probabilistic framework for predicting the fluid loading and structural response of coastal structures at a community level. The research team have validated this framework against existing experimental data, assessed the effects of bathymetry and community layout on flow, refined the models to include force predictions, and extended probabilistic tsunami hazard assessment methods to include fluid loading criteria.

The HWRL EF assisted the researchers at the University of Washington (UW) to modify an existing apparatus and model specimen for use in their project, substantially reducing costs. The modifications allowed the researchers to study the structural properties of the building and the effects of macro-roughness (shielding of other buildings), and waterborne debris (Figure 7). The experiments incorporated the simulation of breaking and non-breaking waves on a fully instrumented elevated coastal structure. One postdoctoral scholar, 4 Ph.D. students, and 2 MSc students were involved in the testing phase of the project. Subsequent to the testing phase, the HWRL EF leadership organized a series of monthly teleconferences with the UW team to assist with the subsequent data analysis and publication phase. To date, the project has led to the publication of 3 peer-reviewed journal papers (all co-authored with UW and OSU teams) and 1 conference proceedings (Lomonaco et al., 2018; Alam et al., 2020; Shekhar et al., 2020; Winter et al., 2020). Significantly, the project led to the successful submission of the project, NSF-1933184 "Understanding and Quantifying Structural Loading from Tsunami-Induced Debris Fields" funded to the UW team. UW will use the HWRL EF for this project in 2020-2021.
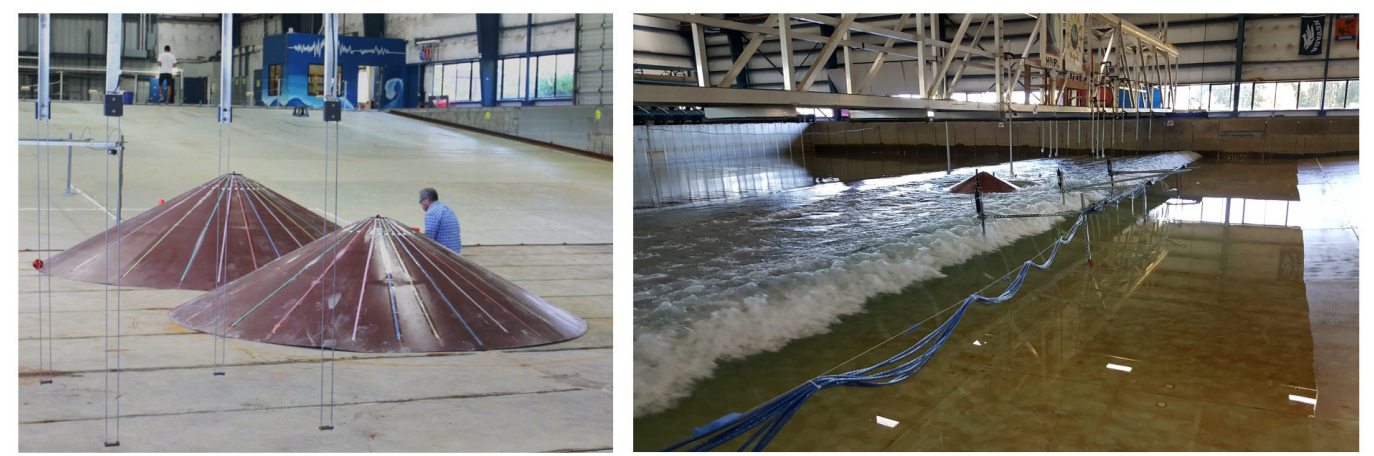

FIGURE 6 | Installation of artificial islands (left) and tsunami tests in DWB (right).


FIGURE 7 | Wave impacting the elevated structure (left) and shielding test (right). 


\section{Collaborative Research: Numerical and Probabilistic Modeling of Aboveground Storage Tanks Subjected to Multi-Hazard Storm Events}

Aboveground storage tanks (ASTs) used to store hazardous materials, such as crude oil, can suffer major damage in severe storms resulting in spills with catastrophic social, environmental, and economic consequences. This research has provided numerical models capable of capturing the complex fluid-structure interaction (FSI) and non-linear system behavior exhibited by ASTs under multi-hazard loads. Furthermore, probabilistic models of tank performance in severe storms are being developed, filling a major gap in risk assessment of this critical industrial and energy infrastructure. The advanced computational resources and collaboration and analysis tools of the National Science Foundation-supported Natural Hazards Engineering Research Infrastructure (NHERI) cyberinfrastructure, DesignSafe-CI.org, will be utilized and enhance in this effort. This project harnessed the synergies of a multi-disciplinary team spanning computational sciences and structural engineering to provide robust numerical models of AST response under multi-flow conditions and to subsequently derive the first models of AST fragility under multiple storm-induced hazards.

The HWRL EF assisted the researchers at Rice University (Rice U) with developing an experimental research plan that would provide benchmark data for their numerical modeling work on ASTs. The HWRL EF utilized existing specimens at the facility from an earlier project and co-developed a research plan with Rice $U$ to represent the hurricane surge and wave conditions representative of their project area in the Gulf of Mexico/Galveston Bay. The measurements included hydrodynamic conditions and pressures surrounding cylindrical ASTs under the action of regular, irregular (long-crested and short-crested) and tsunami-like waves. The test program included two tanks to provide a benchmark case for shielding by neighboring storage tanks (Figure 8). Observations showed the large-diameter tanks to introduce significant diffraction effects. One Ph.D. student was trained on this project. This successful project led to the publication of 4 peer-reviewed journal papers (Bernier and Padgett, 2019a,b; Dominguez et al., 2019; Bernier et al., 2020), 3 conference papers (Bernier and Padgett, 2018a,b, 2019c), 1 Ph.D. dissertation (Bernier, 2019), and was one of the first data sets to receive a DOI at DesignSafe.org (Bernier et al., 2017).

\section{SBIR Phase I: Telescopic Structural Flood Walls}

This Small Business Innovation Research (SBIR) Phase I project aimed to develop, test and validate a retractable telescopic structural wall for applications in flood protection. This technology will enable more resilient infrastructure in floodprone areas. The proposed concept, when validated, will provide a paradigm shift for the prefabricated concrete industry. It will also develop and validate new methods for telescopic interconnection of structural elements. The intellectual merit of this project lies in a unique concept where structural boxes, made out of fiber reinforced concrete, can be deployed telescopically to withstand forces imposed from external sources, and then return to a retracted position. Results have been validated via laboratory tests where lateral and vertical loads, as well as impact loads, were applied. The technical result of Phase I was a working prototype of the telescopic structural flood wall with extension and retraction features, and with the structural capability to withstand the forces from flood events with minimal to no damage.

The HWRL EF Leadership team worked with the researchers to develop a research testing plan for the hydraulic performance of telescopic structural walls for flood (storm surge) and wave action protection. This is one of the first NHERI projects to use both the DWB and the LWF. The hydrostatic support and sealing mechanism were evaluated in the DWB (Figure 9, left), and the stability performance under large-scale breaking waves was evaluated in the LWF (Figure 9, right). This was also the first SBIR proposal tested at this NHERI EF. The data and experience gained from these experiments supported the submission of a Phase II SBIR proposal awarded in 2018, NSF-1758544 "SBIR Phase II: Telescopic Structural Flood Walls" and a presentation in an International Conference (Cueto, 2019).

\section{CAREER: Advancing Multi-Hazard Assessment and Risk-Based Design to Promote Offshore Wind Energy Technology}

Offshore wind energy is a resource of renewable energy that is conveniently accessible to many major population centers but harvesting offshore wind energy currently costs more than traditional sources. The research goal of this Faculty Early Career Development (CAREER) Program grant is to advance knowledge that can lead to reduction in the cost of offshore wind energy through (1) a much sharper understanding and modeling of the spatio-temporal interaction of multiple offshore hazards that impact the system-level performance of offshore wind energy farms to reduce insurance and financing costs, (2) the calculation of novel system-level performance metrics, and (3) the advancement of shallow water wave modeling to mitigate the current reliance on overly conservative design methods. This project has achieved the research goal through fundamental advancements to metamodels (surrogate models) to overcome restrictions that have previously limited the impact of such models in the context of multi-hazard assessment of spatially distributed infrastructure. The research has also explored innovative models that overcome important deficiencies in the modeling of non-linear, highly skewed shallow water waves and their associated hydrodynamic loads, including breaking waves. The research has synthesized these advances and generated system-level performance metrics that will provide a fundamentally different paradigm for designing offshore wind farms.

The HWRL EF Leadership worked with the researcher at Northeastern University to co-develop a testing program 



FIGURE 8 | AST shielding tests DWB (left) and detail of a solitary wave impacting an AST (right).
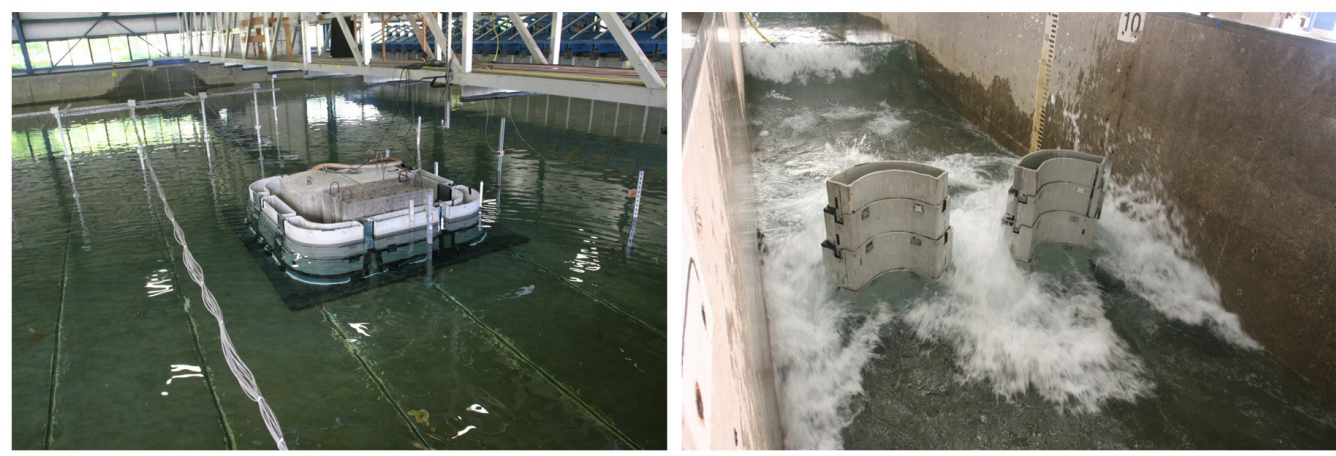

FIGURE 9 | Hydrostatic tests in DWB (left) and breaking wave tests in LWF (right).

for the measurement of hydrodynamic conditions (surface elevation, velocities), and structural response (pressures, multidirectional forces, vibrations, deformations) of a vertical cylinder representing the foundation and support of offshore wind turbines, subject to breaking, broken, and non-breaking tsunami-like waves and storm waves (Figure 10). The testing protocol utilized a unique 6 DOF load cell to capture the structural responses of the specimen under severe wave impact loading. High-speed video and underwater cameras were used to capture details on wave run-up around the cylinder. The adaptable steel model and testing rig for FSI experimentation, is available to the scientific community for future research. This project included the participation of 2 Ph.D. students and a collaboration with University of Massachusetts Amherst, and the publication of 3 peer-reviewed papers in International Conferences (Johlas et al., 2018; Hallowell et al., 2019; Lomonaco et al., 2019).

\section{Transient Rip Current Dynamics: Laboratory Measurements and Modeling of Surfzone Vorticity}

The nearshore region is often compromised by pathogens and excess nutrient supply from terrestrial runoff. Understanding the transport of materials throughout the nearshore region can have important implications for ecosystem and human health.
Previous studies analyzing cross-shelf exchange suggest that transient rip currents are the dominant mechanism driving exchange between the surf zone and the inner shelf. Evidence also suggests that transient rip currents are generated from the coalescence of surf zone eddies, with short-crested waves serving as the source of rotation. This project has utilized laboratory and numerical modeling to study the generation and evolution of surf zone eddies to form transient rip currents. The knowledge of mixing and exchange in the nearshore region will be significantly advanced through this study, which will have important implications for the transport of nutrients, larvae, and pollutants. In collaboration with National Oceanic and Atmospheric Administration scientists, simple predictors of transient rip currents will be developed to improve hazard forecasts for a broad range of environments. This is essential information for human safety as rip currents are the leading cause of fatalities and rescues on beaches. A graduate student has gained valuable training and education through involvement in this project. Outreach activities highlighting rip currents were developed as a part of the O.H. Hinsdale Wave Research Laboratory Outreach Program seeking to broaden participation in Science, Technology, Engineering and Mathematics (STEM).

This project highlights how the NHERI HWRL EF can be used for successfully NSF-funded research beyond the Engineering Directorate. Previous to this funding, the EF worked with the researchers at UW to investigate the suitability of the HWRL 

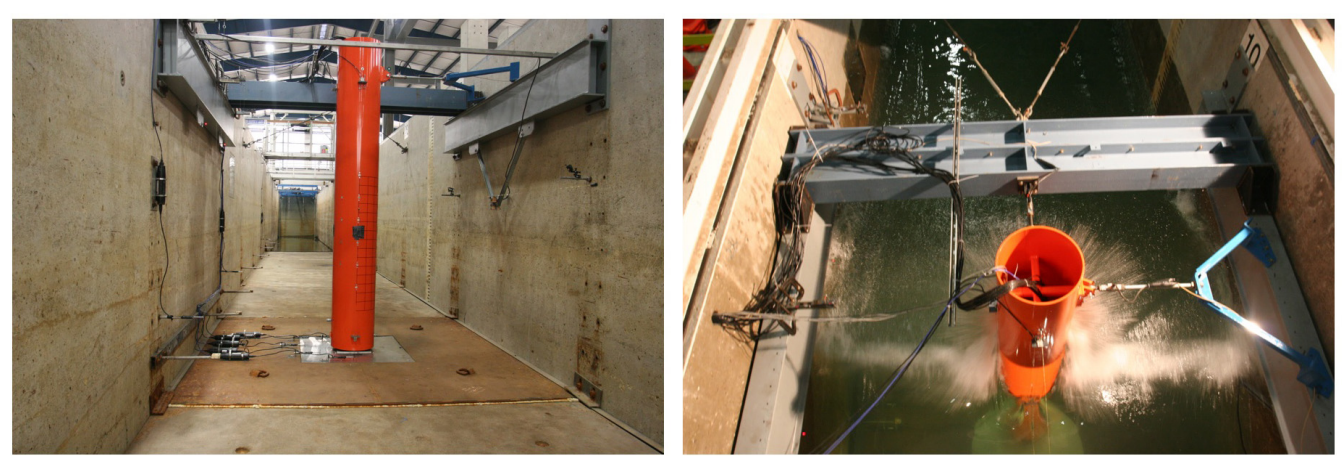

FIGURE 10 | Setup of specimen in LWF (left) and impulsive breaking wave tests (right).

EF for their proposal. For the funded project, rip-currents were generated at the surf-zone with multidirectional irregular waves using a unique modular offshore bar (Figure 11). The HWRL EF worked with the researchers at UW to design a costeffective solution to create these nearshore coastal conditions using the existing 1:10 slope with a modular, fixed outer bar. The components of the offshore bar can be re-used for future research. The investigation allowed for the development of optical techniques to reconstruct the surface elevation and current field using additives (surfactant, floating tracers, dyes), stereographic imagery, infrared cameras, and LiDAR. These experiments were conducted in collaboration with the US Army Corps. of Engineers and the US Navy. One Ph.D. student was supported on this project and one paper has been presented in an international conference (Baker et al., 2020).

\section{Physical Modeling of Submarine Volcanic Eruption Generated Tsunamis}

Tsunamis are normally associated with submarine earthquakes along subduction zones, such as the 2011 Japan tsunami. However, there are significant tsunami sources related to submarine volcanic eruptions. Volcanic tsunamis, like tectonic tsunamis, typically occur with little warning and can devastate populated coastal areas at considerable distances from the volcano. There have been more than 90 volcanic tsunamis accounting for about $25 \%$ of all fatalities directly attributable to volcanic eruptions during the last 250 years. The two deadliest non-tectonic tsunamis in the past 300 years are due to the 1883 Krakatoa eruption in Indonesia with associated pyroclastic flows and Japan's Mount Unzen lava dome collapse in 1792. At the source, volcanic tsunamis can exceed tectonic tsunamis in wave height, but these volcanic tsunamis are subject to significant wave attenuation and dispersion with propagation distance. Most volcanic tsunami waves have been produced by extremely energetic explosive volcanic eruptions in submarine or near water surface settings, or by flow of voluminous pyroclastic flows or debris avalanches into the sea. The recent "orange" alert in July 2015 at the Kick 'em Jenny submarine volcano off Grenada in the Caribbean Sea highlighted the challenges in characterizing the tsunami waves for a potential submarine volcanic eruption. The ultimate long-term goal of this research is to transform assessment and mitigation of the submarine volcanic tsunami hazard through hybrid modeling of submarine volcanic eruption, tsunami generation and propagation along with the potential engulfment and caldera formation.

This experiment involved the design, construction, and implementation of a unique machine to simulate the submarine volcanic eruption for experimental validation of existing mathematical models. A large cylinder with compressed air



FIGURE 11 | Surf zone rip currents in DWB using dye tracers and optical tracking. 
actuators (Figure 12, left) and a system to control stroke and velocity allowed for the generation of tsunamis to simulate different types of erupting volcanoes (Figure 12, right). Researchers from Georgia Tech included measurement of 3D velocities and surface elevation around the volcano, as well as run-up on the shoreline, submarine and overhead digital video for PIV and free surface reproduction. Two Ph.D. students and 2 undergraduate research students were involved in the study. On December 22, 2018, 3 months after the end of the experimental campaign, an underwater eruption and cone collapse of the Anak Krakatoa volcano caused a tsunami with waves up to five meters in height, affecting more than $300 \mathrm{~km}$ (186 mi) of coastline in Sumatra and Java, with 420 casualties, 14,000 people injured and 40,000 displaced. This event demonstrated the value of the research on underwater eruptions and the knowledge gap in the understanding of the generation and propagation of volcanic tsunamis.

\section{Collaborative Research: Wave, Surge, and Tsunami Overland Hazard, Loading and Structural Response for Developed Shorelines, and Experimental Investigation of Wave, Surge, and Tsunami Transformation Over Natural Shorelines}

Inundation from storms like Hurricanes Katrina, Sandy, Matthew or Harvey, and the 2011 East Japan tsunami, has caused catastrophic damage to coastal communities. With increasing coastal population, and trillions of dollars of infrastructure at risk, storms and tsunamis will continue to be threats to coastal communities (Kennedy et al., 2018). Improving community resilience to these Inundation Events (IEs) requires an understanding of how they damage buildings. Prediction of structural damage in IEs can be quite difficult along developed shorelines, where some structures may partially shield buildings behind them, reducing damage in ways that are not easily predictable using the existing state-of-the-art (Kennedy and Westerink, 2019). This project will create new tools to predict structural damage from IEs along developed shorelines. The team from the University of Notre Dame, Oregon State University, and the University of Southern California are developing computerbased predictive methods for detailed building damage using laboratory tests and field data to guide development and validate accuracy. This collaborative project has examined probabilistic structural vulnerability to storm waves and tsunamis in developed regions, where structures are most concentrated but existing models perform poorly due to complex flow transformation around these structures. The laboratory and computational methodologies developed here employed deterministic and stochastic models with scales able to resolve local transformation, and that directly represent relevant processes.

The HWRL EF worked with the research teams to recreate a section of shoreline to allow for the overland flow, including overland surge. This was established by the installation of two large pumps and the construction of return sections to moderate the surge storm. This system allowed for the addition of waves superposed on the currents. On land, the HWRL EF worked with the research teams to create instrumented specimens to measure shielding effects of building and other structures such as seawalls and breakwaters (Figure 13, left). When the project was initially awarded, the HWRL EF worked with the research team to allow a payload project, aimed to study the effect of parcel-size mangrove forests on the attenuation of the incident wave energy (Tomiczek et al., 2020) (Figure 13, right). This ambitious project included experiments of dye dispersion, waterborne debris, macro-roughness sheltering, construction of a coastal community with 100 buildings, effect of a lowcrested seawall, a submerged breakwater, and the sheltering of a non-overtopped seawall. The study considered the effect of regular, irregular and tsunami-like waves, with and without a steady current simulating the overland flow. The collaborative effort supported 2 Ph.D. students, 3 MSc students, 2 undergraduate research students and included the participation of 5 universities, including researchers from Japan and Korea.

\section{Collaborative Research: Physics of Dune Erosion During Extreme Wave and Storm-Surge Events, and Collaborative Research: Implementation Strategies and Performance of Unsaturated Bio-Cemented Dune Sand}

Sand dunes are often the primary and sometimes only "line of defense" for coastal infrastructure and are increasingly constructed and actively managed to protect against extreme events. However, because extreme physical forces only interact with the dune for a relatively short, yet critical time when the water level rises, there is limited understanding on how dune sediments and vegetation can modify hydrodynamic forces and alter beach-dune profile evolution. This research focuses on dune response to a range of water level and forcing conditions that mimic the passage of an extreme storm event. A near prototype-scale laboratory experiment was conducted over a mobile bed in the LWF (Figure 14, left). Physical model studies occurred over a dune with live vegetation (Figure 14, center), and for comparison purposes over a bare dune. Data related to processes ranging from short-term (turbulence) to longer time scales (individual events) were collected and analyzed to develop a fundamental understanding of the fluid-sediment-vegetation dynamics affecting dune stability, as well as damage mitigation strategies for extreme events (Figure 14, right). The collected data will be used to validate the numerical model sedwaveFoam (created in the open-source OpenFOAM framework), capable of simulating the full profiles of sediment transport under realistic waves, and will be extended for dune erosion with or without vegetation.

This was one of the largest sediment transport experiments conducted in a large-scale laboratory, involving the contributions of a large research team of 37 people across several institutions, 
including 15 graduate students, 5 undergraduate and REU students, and 1 High School student and 1 teacher. Although the research dissemination phase is still underway, there was 1 presentation in the Young Coastal Scientists and Engineers Conference-YCSEC 2019 (Moragues and Lomonaco, 2019) and 5 presentations at the recent Ocean Science conference in 2020 (Bond et al., 2020; Converse et al., 2020; Holzenthal et al., 2020; Pontiki et al., 2020; Smith et al., 2020), highlighting the volume of research output. In addition to the planned experiment, two more researchers were able to leverage the installation of the mobile sediment bed to explore a novel approach for dune protection using bio-cementation to stabilize and enhance natural protective structures (Figure 14, right). The research team explored multiple treatment implementation techniques and assess their performance under extreme conditions. The resulting outcome of this work (e.g., Montoya et al., 2020) will provide guidance for enhancing coastal dunes with bio-cementation to prevent damage to infrastructure during extreme events.
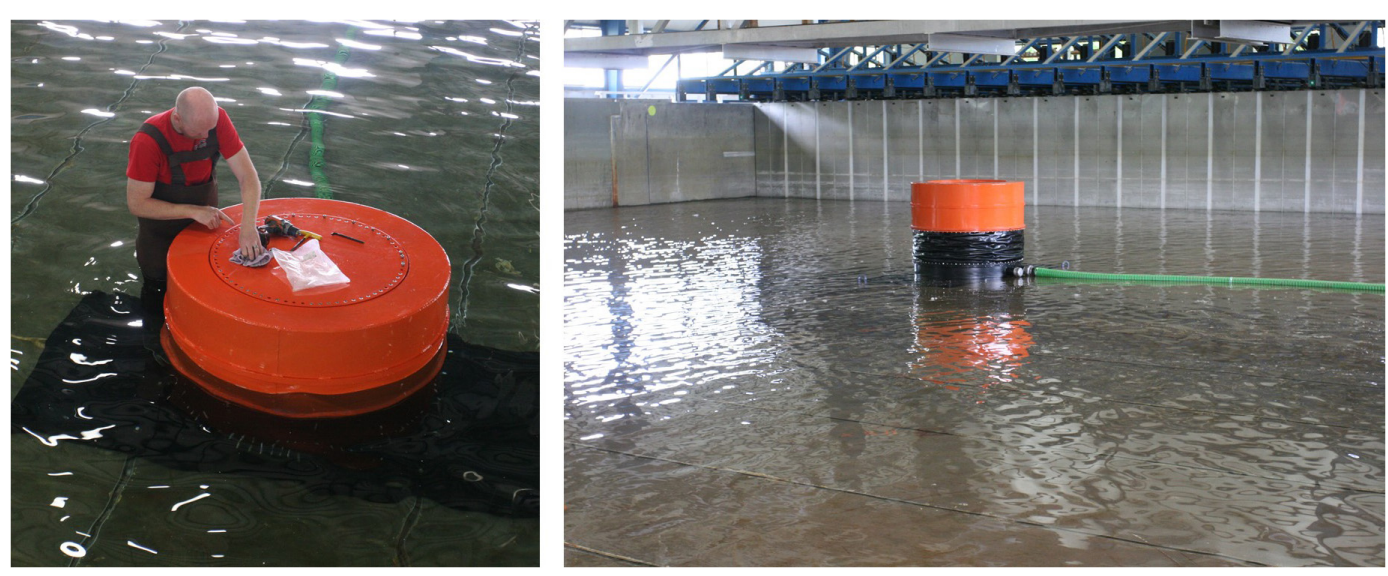

FIGURE 12 | Setup of apparatus in DWB (left) filling of the DWB in preparation for testing with the submarine volcano (right).
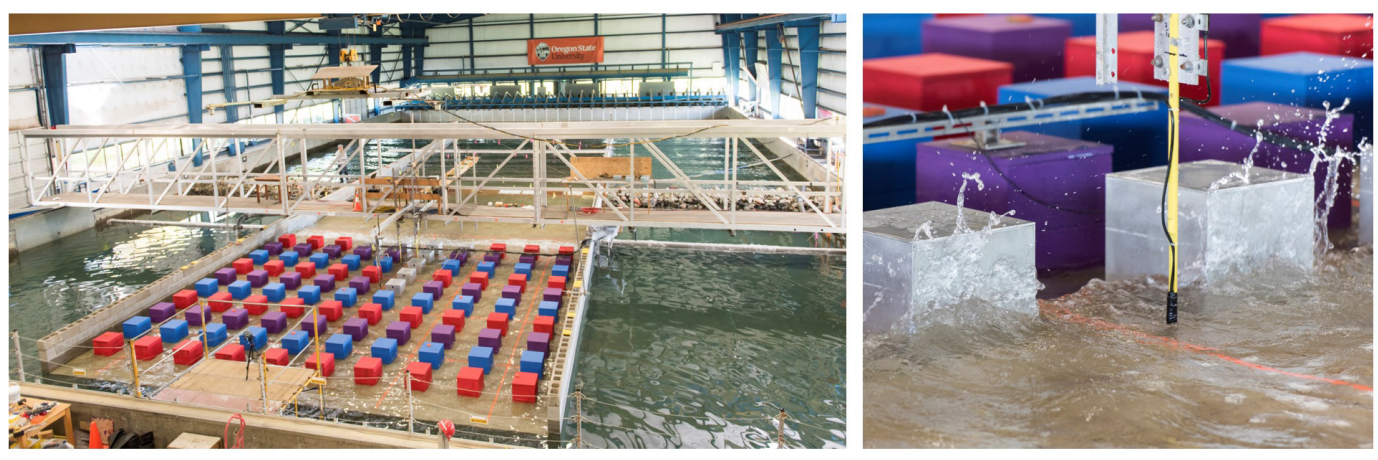

FIGURE 13 | Setup of overland flow in DWB (left) and detail of wave impact on coastal structures (right).
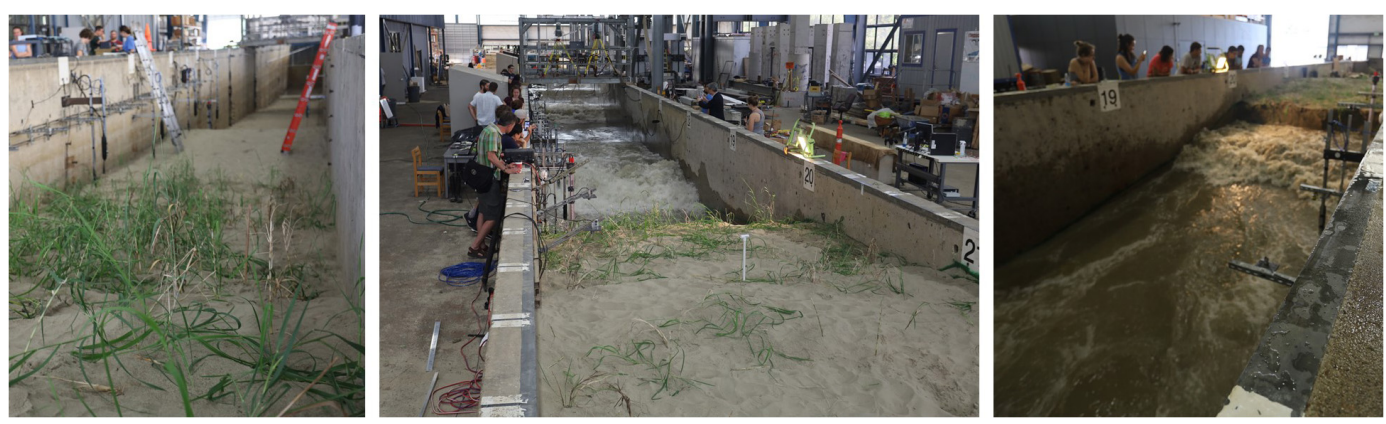

FIGURE 14 | Detail of vegetated duneand instrumentation (left), overview of the LWF during testing (center), and wave impact on dune (right) 


\section{SUMMARY AND CONCLUSION}

The infrastructure and capabilities of the Natural Hazards Engineering Research Infrastructure Experimental Facility at Oregon State University were presented. The facility is an openaccess infrastructure that enables researchers to conduct stateof-art engineering research, education and outreach on natural hazard mitigation for civil infrastructure systems, specifically on tsunamis caused by earthquakes and coastal wave and surge caused by windstorms with two specialized large-scale resources for physical model testing of coastal systems. The facility has the unique ability to conduct physical model testing of the natural and build environment subject to the action of storm waves, surge, tsunamis, and other hazards.

Several selected example research projects recently performed at the HWRL EF to illustrate the facility's capabilities were introduced. These projects included: (1) the assessment of wave impact forces on elevated coastal structures, (2) the effect of offshore islands on the run-up of tsunami events at the coast, (3) sheltering and debris tsunami forces on elevated coastal structures, (4) hydrodynamic forces of storm waves and tsunamis on ASTs, (5) hydrostatic and breaking wave tests of telescopic structural flood walls, (6) impact forces on fixed foundations of offshore wind turbines, (7) modeling of nearshore rip-currents with multi-directional waves, (8) formation and propagation of tsunamis generated by submarine volcanic eruptions, (9) hydrodynamics and wave impact forces on a multi-structure coastal community, and (10) erosion of a vegetated sand dune under the effect of storm waves. The examples present the broad range of experiments performed at the HWRL EF enabling the understanding of the response of the natural and built environment to different sources of coastal hazards.

All tests results and research data are shared through the NHERI DesignSafe ${ }^{1}$.

\section{ETHICS STATEMENT}

Written informed consent was obtained from the individual(s) for the publication of any potentially identifiable images or data included in this article.

\section{AUTHOR CONTRIBUTIONS}

All authors listed have made a substantial, direct and intellectual contribution to the work, and approved it for publication.

\footnotetext{
${ }^{1}$ https://www.designsafe-ci.org/data/browser/public/
}

\section{REFERENCES}

Alam, M. S., Winter, A. O., Galant, G., Shekhar, K., Barbosa, A. R., Motley, M. R., et al. (2020). Tsunami-like wave induced lateral and uplift pressures and forces on an elevated coastal structure. J. Waterway Port Coastal Ocean Eng. 146:04020021. doi: 10.1061/(asce)ww.1943-5460.0000581

Baker, C. M., Moulton, M., Palmsten, M. L., Brodie, K. L., and Kumar, N. (2020). "Remote sensing of transient rip currents and surface waves in a laboratory

\section{FUNDING}

The research reported in this work was supported by several grants from National Science Foundation (NSF). This included CMMI Awards Nos 1266101 and 1301016 Collaborative Research: Fundamental Mechanics and Conditional Probabilities for Prediction of Hurricane Surge and Wave Loads on Elevated Coastal Structures, CMMI Awards Nos. 1538190 and 1538624 Collaborative Research: Non-linear Long Wave Amplification in the Shadow Zone of Offshore Islands, CMMI Award No. 1536198 Probabilistic Assessment of Tsunami Forces on Coastal Structures, CMMI Awards Nos. 1635115 and 1635784 Collaborative Research: Numerical and Probabilistic Modeling of Aboveground Storage Tanks Subjected to Multi-Hazard Storm Events, IIP Award No. 1621727 SBIR Phase I: Telescopic Structural Flood Walls, CMMI Award No. 1552559 Advancing multi-hazard assessment and risk-based design to promote offshore wind energy technology, OCE Award No. 1735460 Transient Rip Current Dynamics: Laboratory Measurements and Modeling of Surfzone Vorticity, OCE Award No. 1459049 Runups of Unusual Size: Predicting Unexpectedly Large Swash Events, CMMI Award No. 1563217 Physical modeling of submarine volcanic eruption generated tsunamis, CMMI Awards Nos. 1661015, 1661052, and 1661315 Collaborative Research: Wave, Surge, and Tsunami Overland Hazard, Loading and Structural Response for Developed Shorelines, CMMI Award No. 1825080 Experimental Investigation of Wave, Surge, and Tsunami Transformation over Natural Shorelines, OCE Awards Nos. 1756449, 1756477, and 1756714 Collaborative Research: Physics of Dune Erosion during Extreme Wave and Storm-Surge Events, CMMI Awards Nos. 1933355 and 1933350 Collaborative Research: Implementation Strategies and Performance of Unsaturated Bio-Cemented Dune Sand, and CMMI Award No. 1726326 Vertical Evacuation Structures Subjected to Sequential Earthquake and Tsunami Loadings. Financial support for the operation of the NHERI Experimental Facility at Oregon State University was provided by NSF under Cooperative Agreement No. CMMI-1519679.

\section{ACKNOWLEDGMENTS}

We are grateful for the support of the National Science Foundation (NSF). Any opinions, findings, and conclusions expressed in this paper are those of the authors and do not necessarily reflect the views of the sponsor (NSF) acknowledged herein.

wave basin," in Ocean Sciences Meeting, (Washington: University of Washington Seattle Campus).

Bernier, C. (2019). Fragility and Risk Assessment of Aboveground Storage Tanks during Storm Events. Ph.D. Thesis, (Houston TX: Rice University).

Bernier, C., and Padgett, J. (2018a). "Dynamic buckling of aboveground storage tanks subjected to hurricane-induced waves." Proceedings of the SEI Structure Congress 2018, (Texas: Texas University). 
Bernier, C., and Padgett, J. E. (2018b). "Probabilistic modeling of aboveground storage tanks under surge and wave loads," in Proceeding of the 36th International Conference on Coastal Engineering, (Baltimore: ASCE).

Bernier, C., and Padgett, J. E. (2019a). Buckling of aboveground storage tanks subjected to storm surge and wave loads. Engin. Struct. 197:109388. doi: 10 . 1016/j.engstruct.2019.109388

Bernier, C., and Padgett, J. E. (2019b). Fragility and risk assessments of aboveground storage tanks subjected to concurrent surge, wave, and wind loads. Reliab. Engin. Sys. Safety 191:106571 doi: 10.1016/j.ress.2019.106571

Bernier, C., and Padgett, J. E. (2019c). "Neural network for estimating storm surge loads on storage tanks," in Proceedings of the 13th International Conference on Applications of Statistics and Probability in Civil Engineering (ICASP 13), (Brighton: ICASP). doi: 10.1016/j.ress.2019.106571

Bernier, C., Lin, Y., Padgett, J. E., Dawson, C. N., Lomonaco, P., and Cox, D. (2017). Large-scale laboratory experiments of wave impacts on vertical cylinders. J. Struct. Engin. 146, 541-943. doi: 10.17603 /DS27D4G

Bernier, C., Padgett, J. E., Lin, Y., Dawson, C. N., Lomonaco, P., and Cox, D. T. (2020). Laboratory experiments of vertical cylinders representative of aboveground storage tanks subjected to waves. J. Struct. Engin. 145:5. doi: 10.1061/(ASCE)ST.1943-541X.0002611

Bond, H., Wengrove, M. E., Puleo, J. A., Feagin, R. A., and Montoya, B. (2020). "Observations of water content and fluid pressure within the interior of an eroding beach dune," in Ocean Sciences Meeting, (Washington: University of Washington Seattle Campus).

Converse, J., Miesse, T. W., and Wengrove, M. E. (2020). "Examining wave attenuation rates and subsurface pore pressures across three marsh restoration sill structures on a sandy bed," in Ocean Sciences Meeting, (Washington: University of Washington Seattle Campus).

Cueto, J. (2019). “Smart walls: telescopic structural walls for flood protection," in 2nd International Interactive Symposium on Ultra High Performance Concrete (2IISUHPC), (Albany, NY: UHPC).

Dominguez, J. M., Altomare, C., Gonzalez-Cao, J., and Lomonaco, P. (2019). Towards a more complete tool for coastal engineering: solitary wave generation in an SPH-based model. Coastal Engin. J. 61, 15-40. doi: 10.1080/21664250. 2018.1560682

Hallowell, S., Arwade, S. A., Johlas, H. M., Lomonaco, P., and Myers, A. T. (2019). "Quantification of predicted wave forces from distant elevation measurements," in Proceeding of the ASME 2019 38th International Conference on Ocean, Offshore and Arctic Engineering OMAE2019 June 9-14, 2019, (Scotland: OMAE).

Han, S., Kaihatu, J. M., Lynett, P. J., and Synolakis, C. (2020). "Runup amplification of full-stroke and dam-break waves on a sloping beach in shadow zone by an offshore island," in Ocean Sciences Meeting, (Washington: University of Washington Seattle Campus).

Holzenthal, E. R., Wengrove, M. E., and Hill, D. (2020). "Sediment transport and wave attenuation behind patches of flexible aquatic vegetation: Findings from a full-scale laboratory experiment," in Ocean Sciences Meeting, (Washington: University of Washington Seattle Campus).

Johlas, H., Hallowell, S., Xie, S., Lomonaco, P., Lackner, M., Arwade, S., et al. (2018). "Modeling breaking waves for fixed-bottom support structures for offshore wind turbines," in Proceedings of the ASME 2018 1st International Offshore Wind Technical Conference, (New York: ASME). doi: 10.1016/j.marstruc.2016.03.003

Kaihatu, J. M., Ardani, S., Goertz, J. T., Venkattaramanan, A., and Sheremet, A. (2018). "Wave dissipation mechanisms in spectral phase-resolving nonlinear wave models," in Advances in Coastal Hydraulics, eds V. Panchang and J. M. Kaihatu (Singapore: World Scientific), 235-262. doi: 10.1142/9789813231283_ 0007

Keen, A. S., and Lynett, P. J. (2019). Experimental study of long wave dynamics in the presence of two offshore islands. Environ. Fluid Mechan. 19, 941-968. doi: 10.1007/s10652-019-09692-y

Kennedy, A., and Westerink, J. (2019). "Coastal inundation events in developed regions," in 2019 Disaster Resilience Symposium, (Gaithersburg, MD: NIST).

Kennedy, A., Westerink, J., Moris Barra, J., and Algan Chella, M. (2018). "Coastal inundation events in developed regions," in 2018 Disaster Resilience Symposium, (Gaithersburg, MD: NIST).

Lomonaco, P., Arduino, P., Barbosa, A., Cox, D., Do, T., Eberhard, M., et al. (2018). "Experimental modeling of wave forces and hydrodynamics on elevated coastal structures subject to waves, surge or tsunamis: the effect of breaking, shielding and debris," in Proceeding of the International Conference on Coastal Engineering, (Baltimore: ASCE).

Lomonaco, P., Maddux, T., Bosma, B., Myers, A. T., Arwade, S. A., Hallowell, S., et al. (2019). "Physical model testing of wave impact forces on fixed foundations of offshore wind turbines," in Proceeding of the International Ocean and Polar Engineering Conference - ISOPE-2019, (Honolulu, HI: ISOPE).

Lynett, P. (2016). Precise Prediction of Coastal and Overland Flow Dynamics: A Grand Challenge or a Fool's Errand. J. Disast. Res. 11, 615-623. doi: 10.20965/ jdr.2016.p0615

Lynett, P., Swigler, D., El Safty, H., Montoya, L., Keen, A., and Son, S. (2019). Study of the three-dimensional hydrodynamics associated with a solitary wave traveling over an alongshore-variable, shallow shelf. J. Waterway Port Coastal Ocean Engin. 145:04019024. doi: 10.1061/(ASCE)WW.1943-5460.0000525

Montoya, B. M., Evans, T. M., Wengrove, M. E., Bond, H., Ghasemi, P., and Yazdani, E. (2020). "Resisting dune erosion with bio-cementation," in Proceedings of the 10th International Conference on Scour and Erosion, (Arlington, VA: ICSE).

Moragues, M. V., and Lomonaco, P. (2019). "Wave reflection and run-up: differences for vegetated and non-vegetated dune," in Poster presented in the Young Coastal Scientists and Engineers Conference Americas, (America: Young Coastal Scientists and Engineers Conference Americas).

NHERI Science Plan (2020). Natural Hazards Engineering Research Infrastructure Five Year Science Plan, 2nd Edn. US: NHERI.

NIST (2014). NIST GCR 14-973-13, Measurement Science R\&D Roadmap for Windstorm and Coastal Inundation Impact Reduction. Available online at: http://www.nist.gov/customcf/get_pdf.cfm?pub_id=915541 (accessed May 12, 2020).

NRC (2011). National Research Council, Grand Challenges in Earthquake Engineering Research: A Community Workshop Report. Washington, DC: The National Academies Press.

NRC (2012). National Research Council, Disaster Resilience: A National Imperative. Washington, DC: The National Academies Press.

NRC (2014). National Research Council, Reducing Coastal Risk on the East and Gulf Coasts. Washington, DC: The National Academies Press.

NSB (2007). National Science Board, Hurricane Warning-The Critical Need for a National Hurricane Research Initiative. Available online at: http://www.nsf.gov/ $\mathrm{nsb} /$ publications/landing/nsb06115.jsp?org=NSF (accaessed on January 12, 2007)

NSTC (2006). National Science and Technology Council, Windstorm Impact Reduction Implementation Plan. Available online at: http: //www.whitehouse.gov/sites/default/files/microsites/ostp/windstorm_impact_ reduction_implementation_plan_final.pdf (accessed June 13, 2020).

Park, H., Do, T., Tomiczek, T., Cox, D. T., and van de Lindt, J. W. (2018a). Numerical modeling of non-breaking, impulsive breaking, and broken wave interaction with elevated coastal structures: laboratory validation and inter-model comparisons. Ocean Engin. 158, 78-98. doi: 10.1016/j.oceaneng.2018.03.088

Park, H., Do, T., Tomiczek, T., Cox, D., and van de Lindt, J. W. (2018b). "Laboratory validation and inter-model comparisons of non-breaking, impulsive breaking, and broken wave interaction with elevated coastal structures using IHFOAM and FLUENT,' in Proceeding of the International Conference on Coastal Engineering, (Baltimore: ASCE).

Park, H., Dt Cox, S., and Shin. (2019). "Physical modeling of horizontal and vertical tsunami forces on the elevated overland structure," in The 3rd International Water Safety Symposium. Journal of Coastal Research, SI-91, eds J. L. Lee, J.S. Yoon, W. C. Cho, M. Muin, and J. Lee, (Florida: Hanyang University), 51-55. doi: 10.2112/si91-011.1

Park, H., Tomiczek, T., Cox, D. T., van de Lindt, J. W., and Lomonaco, P. (2017). Experimental modeling of horizontal and vertical wave forces on an elevated coastal structure. Coastal Engin. 128, 58-74. doi: 10.1016/j.coastaleng.2017.08.001

Pontiki, M., Puleo, J. A., Feagin, R. A., Wengrove, M. E., Hsu, T.-J., and Cox, D. T. (2020)., Vol. "Wave-induced sediment transport in a coupled berm-dune system: a near prototype experiment," in Ocean Sciences Meeting, (Washington: University of Washington Seattle Campus).

Shekhar, K., Winter, A. O., Alam, M. S., Arduino, P., Miller, G. R., Motley, M. R., et al. (2020). Conceptual evaluation of tsunami debris field damming and impact forces. J. Waterway Port Coastal Ocean Eng. 146:04020033. 
Smith, J., Wengrove, M. E., Walter, C., Selker, J. S., and Selker, F. (2020). "Using temperature to infer real-time changes in beach bathymetry - fiber optics in the nearshore," in Ocean Sciences Meeting, (Washington: University of Washington Seattle Campus).

Tomiczek, T., Wargula, A., Jendrysik, M., Goodwin, S., Kennedy, A. B., Lynett, P., et al. (2019a). "Physical model investigation of parcel-scale effects of mangroves on wave transformation and force reduction in the built environment," in Coastal Structures Conference, (Baltimore: ASCE).

Tomiczek, T., Wargula, A., Lomonaco, P., Goodwin, S., Cox, D., Kennedy, A., et al. (2020). Physical model investigation of mid-scale mangrove effects on flow hydrodynamics, pressures, and loads in the built environment. Coastal Eng. 162:103791. doi: 10.1016/j.coastaleng.2020.103791

Tomiczek, T., Wyman, A., Park, H., and Cox, D. T. (2018). "Application and modification of goda formulae for non-impulsive wave forces on elevated coastal structures," in Proceeding of the International Conference on Coastal Engineering, (Baltimore: ASCE).

Tomiczek, T., Wyman, A., Park, H., and Cox, D. T. (2019b). Modified goda equations to predict pressure distribution and horizontal forces for design of elevated coastal structures. J. Waterway Port Coastal Ocean Eng. 145:04019023. doi: 10.1061/(asce)ww.1943-5460.0000527

Winter, A. O., Alam, M. S., Shekhar, K., Motley, M. R., Eberhard, M. O., Barbosa, A. R., et al. (2020). Tsunami-like wave forces on an elevated coastal structure: effects of flow shielding and channeling. J. Waterway Port Coastal Ocean Eng. 146:04020021. doi: 10.1061/(asce)ww.1943-5460.0000581

Conflict of Interest: The authors declare that the research was conducted in the absence of any commercial or financial relationships that could be construed as a potential conflict of interest.

Copyright (c) 2020 Lomonaco, Cox, Higgins, Maddux, Bosma, Miller and Batti. This is an open-access article distributed under the terms of the Creative Commons Attribution License (CC BY). The use, distribution or reproduction in other forums is permitted, provided the original author(s) and the copyright owner(s) are credited and that the original publication in this journal is cited, in accordance with accepted academic practice. No use, distribution or reproduction is permitted which does not comply with these terms. 